\begin{tabular}{|l|l|l|l|l|l|}
\hline J. Tek. Ling & Vol. 13 & No. 2 & Hal. $141-149$ & Jakarta, Mei 2012 & ISSN 1441-318X \\
\hline
\end{tabular}

\title{
TOLERANSI LIMA JENIS RUMPUT TERHADAP MINYAK DAN KAPASITAS DEGRADASINYA DALAM SISTEM FITOREMEDIASI
}

\author{
Budhi Priyanto \\ Balai Teknologi Lingkungan \\ Badan Pengkajian dan Penerapan Teknologi \\ Gedung 412, Kawasan PUSPIPTEK Serpong
}

\begin{abstract}
Abstrak
Sistem fitoremediasi berbasis rumput untuk pengelolaan pencemaran lingkungan di tambang minyak telah diteliti. Lima jenis rumput, yaitu Scirpus grossus, Brachiaria humidicola, Eleusine indica, Paspalum notatum, dan Setaria splendida ditanam pada tanah tercemar minyak lama berkadar 3,1\%. Pengaruh cekaman salinitas dievaluasi dengan menambahkan air formasi $(850 \mathrm{mg} / \mathrm{L}$ TDS) ke dalam tanah. Setelah dua belas minggu, parameter pertumbuhan ditetapkan dan kandungan minyak dalam tanah dianalisis. Hasilnya menunjukkan, bahwa semua jenis rumput dapat tumbuh pada tanah tercemar minyak lama. Di bawah cekaman air formasi, jumlah anakan dan berat kering tunas $B$. humidicola dan $S$. splendida jelas tertekan, tetapi panjang akar meningkat. Sebaliknya, berat kering tunas pada S. grossus meningkat di bawah cekaman salinitas. Berat kering akar semua jenis rumput secara nyata berkurang dengan cekaman salinitas. Nisbah berat kering tunas terhadap akar relatif tidak dipengaruhi oleh salinitas. Kegiatan degradasi minyak dipengaruhi oleh cekaman salinitas. Kandungan minyak yang hilang dari tanah berkisar antara $32 \%$ hingga $50 \%$ pada semua jenis rumput.
\end{abstract}

Kata kunci: pencemaran minyak, fitoremediasi, rumput, air formasi

\begin{abstract}
Experiment to develop a grass based phytoremediation system for environmental management in oil industry has been established in the green house. Five species of grasses, i.e. Scirpus grossus, Brachiaria humidicola, Eleusine indica, Paspalum notatum, dan Setaria splendida, were planted in $6.5 \mathrm{~kg}$ oil polluted Semanggi soil (oil content of $3,1 \%$ ). The effects of salinity were evaluated by adding $800 \mathrm{ml}$ of produced water (850 $\mathrm{mg} / \mathrm{L} T D S$ ) to the soil. Growth parameters of the plants and the remaining oil content in the soil were determined in the end of week 12th after planting. The results indicated that all of the grass species are capable of growing well in the polluted soil. However, under the salinity stress, the number of buds on the stolons or rhizomes and the shoot dry weight of $B$. humidicola and S. splendida are reduced significantly. On the contrary, the root length of the two species is increased; and the shoot dry weight of S. grossus is increased. The root dry weight of all tested species are reduced significantly; however the ratio of shoot dry weight to root dry weight is not influenced by salinity stress. Overall, the oil removal rate from the soil is in the range of 32\% to 50\%; S. grossus and S. splendida are being the best. The oil degradation activity of the two species is slightly increased under salinity stress condition.
\end{abstract}

Key words: oil polluted soil, phytoremediation, grass, produced water 


\section{PENDAHULUAN}

\subsection{Latar belakang}

Kegiatan penambangan selalu membawa resiko terjadinya pencemaran terhadap lingkungan, sehingga komitmen dari perusahaan pertambangan besar untuk memelihara lingkungan selalu dituntut dilaksanakan ${ }^{1)}$. Pada tambang minyak rakyat di sumur tua Blok Cepu, pengelolaan lingkungan yang baik tidak dilaksanakan. Di tambang rakyat tersebut limpasan mengandung minyak tersebar di lingkungan sekitar sumur dan air formasi dibuang langsung ke sungai. Mengingat nilai keekonomian dari sumur tua relatif kecil, maka diperlukan alternatif teknologi yang membantu mengatasi masalah pencemaran minyak, terutama di lingkungan sumur tua.

Fitoteknologi dipandang sebagai salah satu alternatif yang relatif rendah biaya di dalam pengelolaan pencemaran lingkungan ${ }^{2,3)}$. Rumput merupakan salah satu golongan tumbuhan yang banyak dipakai di dalam fitoremediasi minyak bumi karena dipandang efektif dalam mendegradasi minyak. Aktivitas enzimatik dan populasi mikroba di daerah perakaran tiga jenis rumput, yaitu Pannicum, Eleusine indica, dan Festuca, ternyata meningkat dan degradasi minyak dalam tanah yang ditanami meningkat sebesar 3-4 kali lebih tinggi daripada di tanah yang tidak ditanami ${ }^{4}$. Rumput Lolium perenne, Poa pratensis, Festuca rubra dan Festuca ovina merupakan ekosistem yang mendukung pertumbuhan mikroba di rizosfer hingga dua kali lipat, terutama jenis mikroba yang efektif mendegradasi hidrokarbon. Sistem berbasis rumput tersebut mendegradasi komponen toksik yang terdapat dalam oil shale, seperti senyawa fenol dan PAH (polycyclic aromatic hydrocarbon)5). Laporanlaporan lain menguatkan peranan rizosfer rumput sebagai penyedia ekosistem yang mendorong terjadinya degradasi minyak ${ }^{6,7}$.

\subsection{Tujuan}

Dalam percobaan ini akan dilihat pengaruh penambahan air salin terhadap pertumbuhan rumput dan degradasi minyak. Toleransi rumput terhadap minyak dinilai dari komponen pertumbuhan vegetatif dan kapasitas degradasi minyak dinilai dari sisa minyak yang ada dalam tanah pada akhir inkubasi.

\section{BAHAN DAN METODE}

\subsection{Sumber tanah dan penyiapan medium tanam}

Tanah yang digunakan adalah tanah tercemar minyak bumi yang diambil dari sekitar sebuah sumur minyak milik PT Pertamina di Desa Semanggi, Kabupaten Blora. Hasil analisis menunjukkan, bahwa kandungan minyak total (TPH, total petroleum hydrocarbon) dari tanah tercemar ini adalah $3,1 \%$ (bobot/bobot kering angin).

Tanah dikeringanginkan selama dua minggu di dalam rumah kaca. Tanah kering kemudian diayak dengan ukuran lubang ayakan $0,5 \mathrm{~cm}$. Untuk memperoleh medium tanam yang gembur, kompos yang terbuat dari daun pohon yang dikumpulkan di Kawasan Puspiptek, Serpong, ditambahkan sebanyak $25 \%$ dari berat tanah tercemar (tanah:kompos $=4: 1$ ). Campuran medium diaduk merata dan kemudian sebanyak 6,5 $\mathrm{kg}$ medium dipindahkan ke dalam sebuah pot plastik (ukuran $25 \times 35 \times 10 \mathrm{~cm}$ ) yang tidak mempunyai lubang pembuangan di bagian bawah. Untuk mencapai $60 \%$ kapasitas lapangan, sebanyak $3.000 \mathrm{ml}$ air atau campuran air dan air formasi ditambahkan.

\subsection{Perlakuan dalam percobaan}

Percobaan ini dilaksanakan dengan mengikuti pola percobaan faktorial dengan 2 faktor, yaitu jenis rumput (5 level jenis) dan cekaman salinitas (penambahan air formasi). 
Jenis rumput yang digunakan adalah satu jenis rumput dari ekosistem lahan basah, yaitu walingi (Scirpus grossus) yang diambil dari rawa di Desa Cogreg, Kecamatan Gunungsindur, Kabupaten Bogor. Empat jenis rumput lain adalah rumput pakan ternak, yaitu Brachiaria humidicola, Paspalum atratum, Setaria splendida, dan Eleusine indica. Semua rumput pakan ternak itu diperoleh dari Fakultas Peternakan IPB.

Sebelum ditanam pada pot perlakuan, rumput diaklimatisasi terlebih dahulu selama satu bulan dalam pot pembibitan. Satu batang atau ruas rumput ditanam dalam pot pembibitan yang berisi medium tanah yang sama dengan yang dipakai dalam pot perlakuan. Tujuan dari aklimatisasi tanaman ini adalah untuk menghindari kejutan dan cekaman terhadap tanaman yang diakibatkan oleh pencabutan diikuti dengan paparan terhadap salinitas (kadar garam) tinggi. Untuk meniru keadaan cekaman salin sebesar $850 \mathrm{mg} / \mathrm{l}$ TDS, maka banyaknya air formasi yang harus ditambahkan adalah sebanyak $800 \mathrm{ml}$.

Pot dipupuk dengan pupuk lengkap Hyponex dengan kadar N, P, dan $\mathrm{K}$ masingmasing sebesar $50 \mathrm{~kg} \mathrm{~N}, 10 \mathrm{~kg}, \mathrm{P} 2 \mathrm{O} 5$ dan 40 $\mathrm{kg} \mathrm{K2O.} \mathrm{Pupuk} \mathrm{diberikan} \mathrm{dua} \mathrm{kali,} \mathrm{masing-}$ masing pada saat tanam dan 6 minggu setelah tanam. Penambahan air dilakukan setiap 2-4 hari sebanyak 0,5 I bergantung pada pertumbuhan tanaman dan cuaca.

Pengawasan terhadap hadirnya hama dan penyakit dilakukan secara visual. Bila tampak gejala serangan oleh hama, daun dan batang rumput diolesi dengan akarisida dan insektisida kontak dengan kadar seperti pada label kemasan pestisidanya. Aplikasi pestisida tidak dilakukan dengan penyemprotan untuk menjaga agar tidak ada jatuhan pestisida ke atas tanah.

Jumlah tunas per rumpun atau per tanaman induk dihitung setiap 2 minggu. Setelah masa pertumbuhan selama 12 minggu, rumput dicabut dari pot, perakaran dibersihkan dari partikel tanah yang masih melekat. Biomassa segar tunas dan akar ditetapkan dengan penimbangan. Panjang tunas dan akar diukur dengan mistar. Tunas dan akar kemudian dimasukkan dalam oven untuk dikeringkan pada suhu $60^{\circ} \mathrm{C}$ selama 3-10 hari. Berat kering ditetapkan dengan penimbangan.

\subsection{Analisis fisiko-kimia}

Pengukuran $\mathrm{pH}$ dilakukan menurut metode yang diterangkan dalam SNI 066989.11-20048) dan salinitas ditetapkan menurut metode yang diterangkan dalam SNI 06-6989.1-2004\%). TPH ditetapkan secara gravimetri menurut metode yang diterangkan dalam EPA Test Method $3540 \mathrm{C}^{10}$.

\subsection{Analisis data}

Data dianalisis merujuk pada prosedur yang diterangkan oleh Steel dan Torrie ${ }^{11)}$. Signifikansi perbedaan rerata perlakuan dipertimbangkan pada level $5 \%$ dan $1 \%$.

\section{HASIL DAN PEMBAHASAN}

\subsection{Pertumbuhan vegetatif rumput}

Jumlah tunas dan anakan per rumpun menunjukkan kemampuan tanaman untuk menguasai sebidang lahan tempat tumbuhnya. Jumlah anakan per rumpun pada rumput yang diamati pada akhir minggu ke-12 memperlihatkan variasi yang besar di antara jenis rumput (Gambar 1). Tampak, bahwa B. humidicola dan $S$. grossus membentuk tunas terbanyak, yaitu masing-masing 24 dan 25 tunas per tanaman. Namun habitus kedua jenis rumput tersebut sangat berbeda. Setelah 12 minggu pertumbuhan, $B$. humidicola membentuk karpet rumput yang rapat, karena jenis ini membentuk stolon yang menjalar di atas tanah dan pada setiap ruas akan terbentuk tunas baru yang berakar. Tunas baru ini adalah cabang yang akhirnya akan membentuk anakan-anakan baru yang melebar menyebar di sekeliling induknya. 
Sebaliknya, sebagai jenis rumput tegak yang biasa ditemukan di lahan basah, S. grossus membentuk stolon pendek dalam tanah dan pada setiap ujungnya terbentuk tunas baru dengan perakarannya. Dengan cara ini, $S$. grossus dengan cepat membentuk koloni rapat dan tegak dengan kuat.

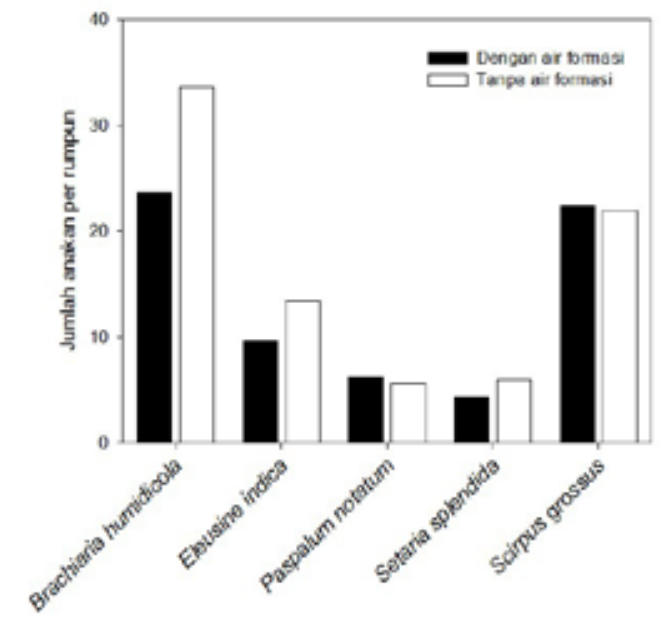

Gambar 1. Jumlah anakan per rumpun pada akhir minggu ke-12 dari rumput yang ditanam di tanah tercemar minyak dan tercekam salinitas dari air formasi

Ketiga jenis rumput yang lain membentuk lebih sedikit anakan, yaitu masing-masing 12,6 , dan 5 anakan pada bertutur-turut $E$. indica, $P$. notatum, dan $S$. splendida. Rumput bahia ( $P$. notatum) mempunyai akar rimpang kuat dengan ruas-ruas yang rapat. Rizoma ini dapat bercabang-cabang dan perakarannya tebal dan kuat. Dengan demikian dalam jangka panjang jenis ini akan mengikat tanah dengan kuat lewat rantaian akar dan rizomanya yang tebal dan kuat. Baik E. indica maupun $S$. splendida mempunyai stolon pendek sehingga pertumbuhan anakan (tunas) rapat di sekitar induknya.

Seperti yang tampak dalam Tabel 1, terdapat pengaruh yang sangat signifikan dari jenis rumput terhadap jumlah anakan yang terbentuk di dalam lingkungan yang berminyak. Sedangkan penambahan air formasi, walaupun memberikan indikasi menekan pembentukan tunas anakan, namun secara statistika pengaruhnya tidak signifikan. Tampak, bahwa penambahan air formasi menekan pembentukan anakan baru pada $B$. humidicola, E. indica, dan S. splendida.

Tabel 1. Nilai $F$ dari berbagai parameter yang diamati pada percobaan ini

\begin{tabular}{|c|c|c|}
\hline \multirow{2}{*}{ Parameter } & \multicolumn{2}{|c|}{ Perlakuan } \\
\cline { 2 - 3 } & Jenis rumput & Air formasi \\
\hline $\begin{array}{c}\text { Jumlah } \\
\text { anakan }\end{array}$ & 10,07 & 1,01 \\
\hline $\begin{array}{c}\text { Panjang } \\
\text { tunas }\end{array}$ & 25,45 & 0,45 \\
\hline $\begin{array}{c}\text { Bobot kering } \\
\text { tunas }\end{array}$ & 16,37 & 0,4 \\
\hline Panjang akar & 10,22 & 2,82 \\
\hline $\begin{array}{c}\text { Bobot kering } \\
\text { akar }\end{array}$ & 4,09 & 4,39 \\
\hline $\begin{array}{c}\text { Nisbah } \\
\text { tunas:akar } \\
\text { (panjang) }\end{array}$ & 5,18 & 0,66 \\
\hline $\begin{array}{c}\text { Nisbah } \\
\text { tunas:akar } \\
\text { (bobot } \\
\text { kering) }\end{array}$ & 8,05 & 1,14 \\
\hline $\begin{array}{c}\text { Persentase } \\
\text { kehilangan } \\
\text { minyak }\end{array}$ & 1,83 & 2,57 \\
\hline $\begin{array}{c}\text { Nilai F tab. } \\
\text { (a=5\%) }\end{array}$ & 2,93 & 4,41 \\
\hline \multicolumn{2}{|c|}{. } & \\
\hline
\end{tabular}

Panjang tunas, yang diukur dari pangkal batang pertama hingga ujung stolon atau daun, sangat bervariasi di antara jenis rumput (Gambar 2 dan Tabel 1). Pada jenis seperti $E$. indica yang berhabitus roset, panjang tunas menjadi sangat pendek. Sedangkan pada jenis yang membentuk daun atau stolon panjang, panjang tunasnya menjadi sangat panjang. Tampak, bahwa penambahan air formasi cenderung sedikit mendorong penambahan panjang tunas, walaupun secara statistika tidak signifikan. 


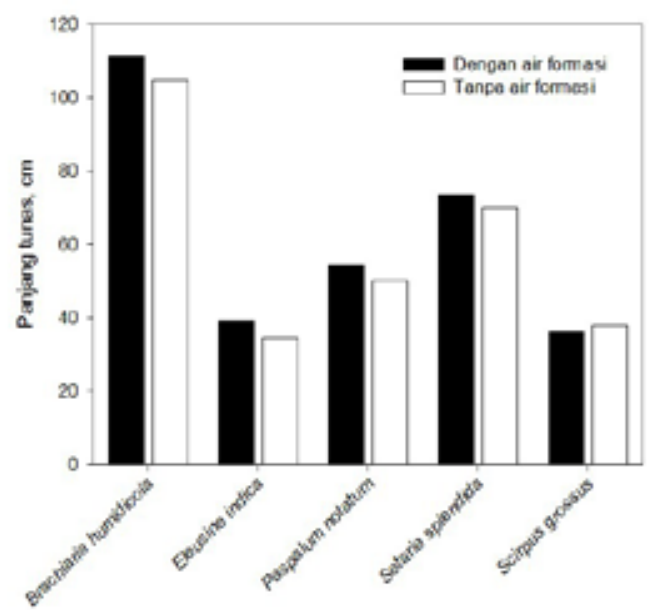

Gambar 2. Panjang tunas tanaman rumput pada akhir minggu ke-12 setelah ditanam di tanah tercemar minyak dan tercekam salinitas dari air formasi

Pada Gambar 3 tampak, bahwa biomassa (berat kering) $S$. grossus adalah tertinggi di antara rumput yang diamati, dan biomassa $B$. humidicola mengikuti di belakangnya. Hal ini menunjukkan, bahwa walaupun panjang tunas $S$. grossus lebih kecil daripada $B$. humidicola, namun penimbunan massa jaringan tanamannya sangat besar. Biomassa E. indica adalah yang terkecil, sesuai dengan panjang tunas dan jumlah anakan yang kecil pula. Di bawah pengaruh cekaman salinitas, ternyata $B$. humidicola, E. indica, dan S. splendida menimbun lebih sedikit biomassa dibanding dengan keadaan tanpa tekanan. Sebaliknya, pada S. grossus terjadi respon penambahan biomassa yang besar, sedangkan $P$. notatum relatif tidak terpengaruh oleh cekaman salinitas. Meskipun demikian ternyata secara statistik tidak ada perbedaan akumulasi biomassa yang signifikan di antara perlakuan cekaman salinitas.

Akar merupakan organ tanaman yang mengalami kontak langsung dengan pencemar minyak di dalam tanah. Dapat diduga, bahwa pertumbuhan akar mencerminkan kemampuan adaptasi tumbuhan pada tanah tercemar minyak.
Seperti tampak pada Gambar 4, panjang akar tanaman rumput bervariasi dan secara statistika (Tabel 1) berbeda secara signifikan di antara jenis rumput. Di antara jenis rumput yang diuji, ternyata $B$. humidicola mempunyai panjang akar terbesar, sedangkan akar S. grosus relatif pendek. Panjang akar diduga berhubungan dengan kemampuan fitoremediasi dari suatu jenis rumput dan rumput dengan akar panjang dianggap mempunyai keuntungan dalam degradasi atau penyerapan pencemar dari dalam tanah ${ }^{2}$. Namun, selain panjang akar, karakteristik vegetatif lain yang penting adalah kerapatan akar, yang dapat dicerminkan dari jumlah akar dan biomassa akar.

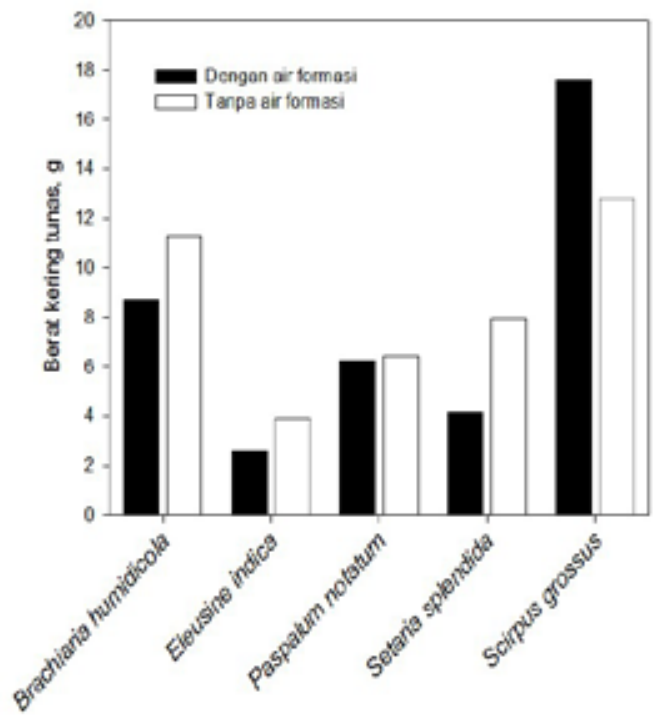

Gambar 3. Berat kering tunas tanaman rumput pada akhir minggu ke-12 setelah ditanam di tanah tercemar minyak dan tercekam salinitas dari air formasi

Pada Gambar 4 terlihat pula, bahwa pada umumnya di bawah cekaman salinitas, tanaman rumput yang diuji cenderung membentuk akar yang lebih panjang. Hal ini merupakan respon agar tanaman dapat menjangkau sumberdaya air dan hara dalam tanah yang lebih besar. $B$. humidicola 


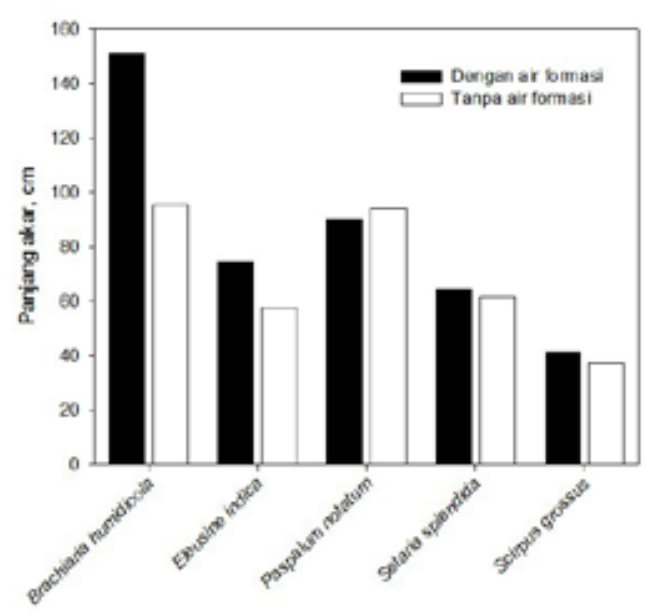

Gambar 4. Panjang akar tanaman rumput pada akhir minggu ke- 12 setelah ditanam di tanah tercemar minyak dan tercekam salinitas dari air formasi

ternyata cenderung untuk membentuk akar lebih panjang dibandingkan jenis rumput yang lain.

Menurut konsep fitoremediasi, mikroorganisme yang berasosiasi dengan rizosfer mempunyai peranan penting dalam degradasi pencemar minyak di dalam tanah2. Oleh karena itu parameter panjang dan biomassa akar sangat penting untuk diperhatikan. Seperti tampak pada Gambar 5 , akumulasi biomassa akar terbesar terjadi pada $S$. grossus, diikuti berturut-turut oleh S. splendida, P. notatum, E. indica, dan $B$. humidicola. Jadi, jenis terakhir ini mempunyai panjang akar terbesar namun biomassa akarnya terkecil. B. humidicola mempunyai perakaran yang relatif halus dan kecil. Sebaliknya, S. grossus dan S. splendida, yang mempunyai akar lebih pendek, ternyata mengakumulasi lebih banyak biomassa di akar daripada jenis rumput yang lain. Akumulasi biomassa akar pada umumnya tertekan dengan penambahan air formasi. Secara statistika, pengaruh pemberian air formasi (cekaman salinitas) menekan dan cenderung signifikan (Tabel 1). Data pada Gambar 5 menunjukkan, bahwa penurunan biomassa akar pada $S$. grossus dan $P$. notatum relatif lebih kecil daripada jenis rumput yang lain.

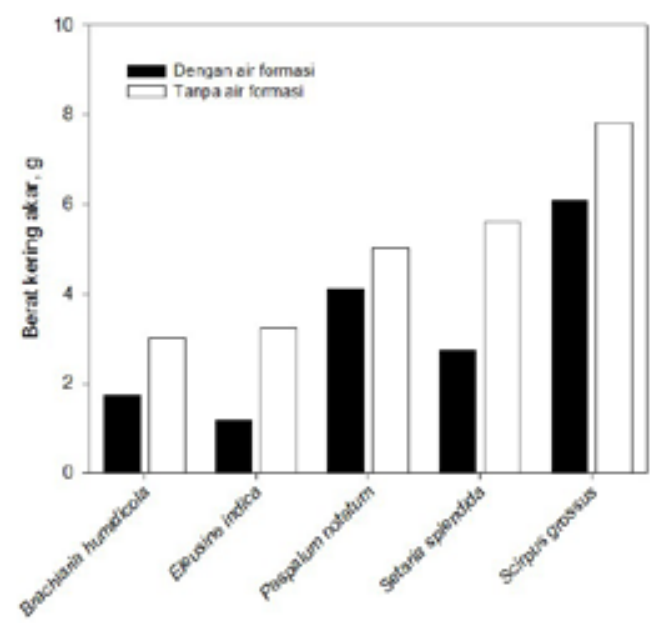

Gambar 5. Berat kering akar tanaman rumput pada akhir minggu ke-12 setelah ditanam di tanah tercemar minyak dan tercekam salinitas dari air formasi

Pemilihan jenis tanaman untuk fitoremediasi minyak bukan hanya ditentukan oleh besarnya akumulasi biomassa tunas, yang mencerminkan pertumbuhan cepat dan kuat, melainkan yang lebih penting adalah akumulasi biomassa akar. Perbandingan laju pertumbuhan tunas dan akar merupakan gambaran dari partisi alokasi sumberdaya yang dipunyai oleh tumbuhan. Dalam kaitannya dengan fitoremediasi, lebih disukai jenis tumbuhan yang mengalokasikan banyak sumberdaya ke sistem perakarannya.

Seperti yang terlihat dalam Tabel 1 dan Gambar 6, nisbah panjang tunas terhadap panjang akar pada akhir minggu ke-12 sangat dipengaruhi oleh jenis rumput. Jenis rumput S. grossus, S. splendida, dan B. humidicola dalam keadaan tercekam minyak cenderung mempunyai panjang akar yang kurang lebih setara dengan panjang tunas. Sebaliknya, $E$. indica dan $P$. notatum mempunyai akar yang lebih panjang dibanding dengan tunas.

Pilihan alokasi sumberdaya ke tunas 
atau ke akar dapat dilihat dari respon nisbah berat kering tunas terhadap akar. Angka yang besar dari nisbah tersebut mencerminkan alokasi lebih besar kepada tunas daripada akar, dan sebaliknya. Seperti yang terlihat dalam Gambar 7, nisbah berat kering tunas terhadap akar bervariasi antar jenis rumput. Secara keseluruhan terlihat adanya tiga pola, yaitu angka nisbah lebih dari 4 (berarti tanaman mengalokasikan biomassa tunas 4 kali lebih besar daripada biomassa akar) seperti yang terjadi pada $B$. humidicola. Angka nisbah sebesar lebih kurang 2 terjadi pada S. grossus dan P. notatum. Sedangkan S. splendida dan E. indica mengalokasikan berat kering kurang lebih sama baik ke tunas maupun ke akar. Cekaman salinitas tidak mengubah alokasi biomassa pada semua jenis rumput yang diamati.

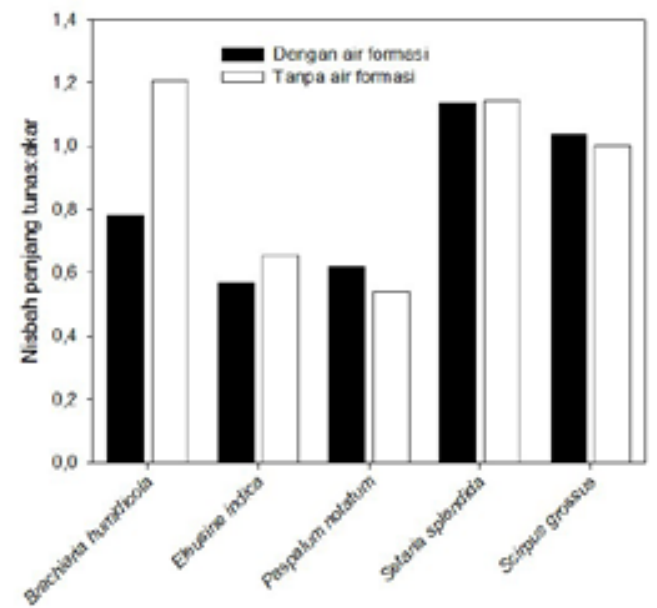

Gambar 6. Nisbah panjang tunas terhadap panjang akar tanaman rumput pada akhir minggu ke-12 setelah ditanam di tanah tercemar minyak dan tercekam salinitas dari air formasi

Perbedaan besarnya alokasi sumberdaya ke akar dan tunas ini penting untuk diperhatikan karena penelitian menunjukkan, bahwa pertumbuhan akar erat hubungannya dengan pertumbuhan mikroorganisme rizosfer yang mampu mendegradasi minyak bumi ${ }^{4,6,7)}$.

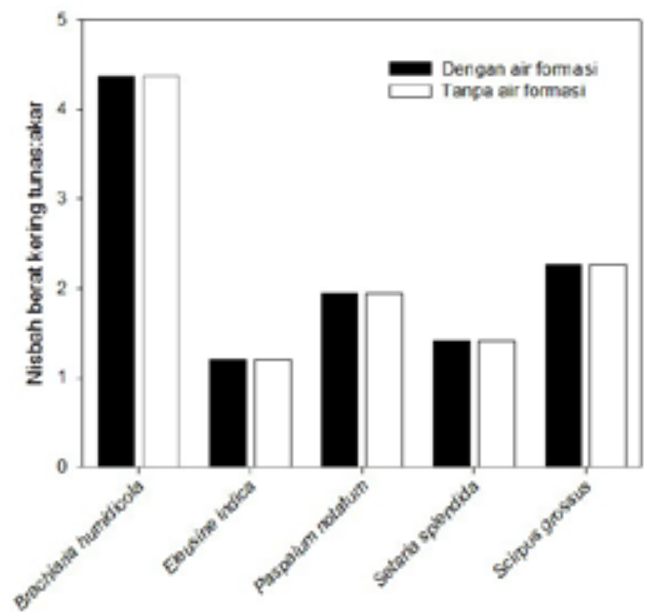

Gambar 7. Nisbah berat kering tunas terhadap berat kering akar tanaman rumput pada akhir minggu ke-12 setelah ditanam di tanah tercemar minyak dan tercekam salinitas dari air formasi

Secara statistika tidak terdapat perbedaan signifikan di antara perlakuan jenis rumput dan penambahan air formasi. Tetapi pengamatan rinci terhadap komponen-komponen sumber keragaman menghasilkan dugaan, bahwa terdapat interaksi antara penambahan air formasi dan jenis rumput. Degradasi minyak pada perlakuan rumput $E$. indica dan $B$. humidicola menurun tajam dengan penambahan air formasi. Sebaliknya, penambahan air formasi pada perlakuan rumput $S$. splendida dan S. grossus meningkatkan laju degradasi. Sedangkan laju degradasi pada rumput $P$. notatum sedikit berkurang dengan adanya penambahan air formasi.

Seperti yang terlihat pada Gambar 4, di bawah cekaman salinitas panjang akar rumput $B$. humidicola dan $E$. indica cenderung bertambah. Diduga, meningkatnya biomassa akar mempunyai potensi untuk peningkatan dalam laju degradasi minyak. Hasil penelitian terdahulu menunjukkan, bahwa kualitas pertumbuhan akar sangat penting di dalam menentukan makna peranan rumput pada fitoremediasi minyak. Pertumbuhan akar rumput memacu kegiatan mikroorganisme 


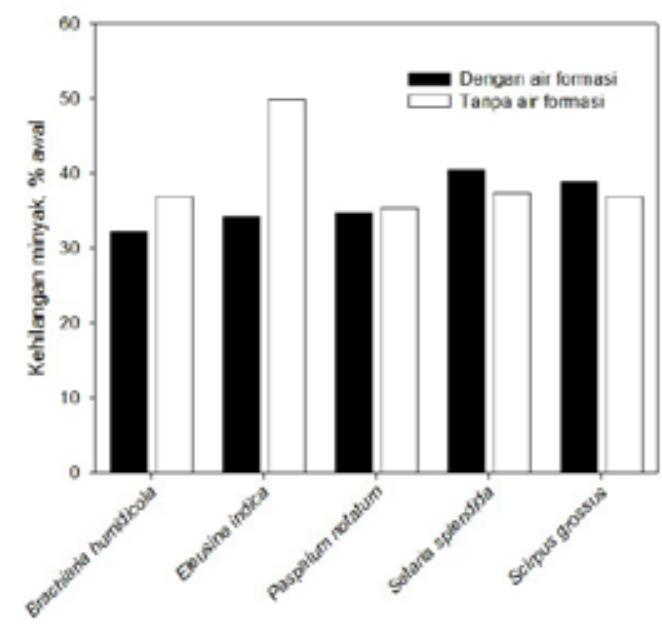

Gambar 8. Penghilangan kandungan minyak dari tanah tercemar minyak yang ditanami rumput pada akhir minggu ke-12 setelah ditanam di tanah tercemar minyak dan tercekam salinitas dari air formasi

yang pada akhirnya akan mendorong terjadinya biodegradasi TPH secara lebih cepat. Selain itu, hilangnya TPH terutama berlangsung pada masa ketika laju pertumbuhan akar tinggi dan akan menurun dengan menurunnya kecepatan pertumbuhan akar ${ }^{12)}$. Pada rumput yang ditanam di tanah tercemar minyak solar ${ }^{13)}$, akar cenderung menyukai bagian tanah di antara zona kontaminasi dan akar akan tumbuh cepat pada bagian tanah yang tidak terkontaminasi. Bila tidak tersedia bagian tanah yang tidak terkontaminasi, akar akan tumbuh menembus zona kontaminasi dalam rangka mencari kemungkinan dapat menjangkau daerah tak terkontaminasi. Tampaknya, pertumbuhan akar yang cepat dari $B$. humidicola dan $E$. indica terkait dengan upaya rumput mencari daerah yang tidak terkontaminasi. Kemungkinan pemanjangan akar ini tidak diimbangi dengan pertumbuhan populasi mikroorganisme yang efektif di rizosfer.

Pada percobaan ini minyak dan air formasi disebar merata dengan cara mengaduk medium tanah secara seksama. Dengan demikian akar rumput selalu dihadapkan pada zona terkontaminasi pada seluruh bagian pot. Karena tinggi medium dalam pot hanya $10 \mathrm{~cm}$, dijumpai bahwa akar cenderung untuk mengumpul di bagian bawah pot pada $E$. indica, $P$. notatum, dan S. splendida. Akar rumput lain, yaitu $B$. humidicola dan Scirpus grossus cenderung agak menyebar serta sebagian mengumpul di dasar pot. Pada pengamatan tim fitoremediasi BTL di percobaan lapangan dengan minyak berat di PT Siak Bumi Pusako, Zamrud, Riau, dijumpai bahwa konsentrasi minyak pada daerah perakaran rumput cenderung lebih rendah seperti yang ditunjukkan oleh pengamatan secara visual (Tuti Suryati, 2010, komunikasi pribadi).

\section{KESIMPULAN DAN SARAN}

1. Konsekuensi agronomis dari hasil penelitian ini terkait dengan tujuan fitoremediasi adalah diperlukan pengolahan tanah agar sebaran kontaminasi minyak merata dan pertumbuhan akar terpacu dengan gemburnya tanah. Selain itu jenis rumput yang terpilih harus mempunyai karakter mudah berasosiasi dengan mikroorganisme yang efektif.

2. Rumput mempunyai kemampuan untuk menghilangkan minyak dari tanah antara $32 \%$ hingga $50 \%$ dalam waktu 12 minggu.

3. Dari sisi morfologi, sifat perakaran, dan toleransi terhadap salinitas, $P$. notatum adalah terbaik, diikuti oleh $S$. grossus, $S$. splendida, E. indica, dan B. humidicola.

4. Dari sisi kapasitas mendegradasi minyak, jenis rumput Paspalum notatum dan Scirpus grossus dapat dianjurkan untuk diteliti lebih lanjut.

\section{UCAPAN TERIMAKASIH}

Terimakasih dan penghargaan disampaikan kepada Sati Suyanti, Atang, dan Yunus untuk bantuan dalam pelaksanaan 
percobaan di rumah kaca dan analisis bahan.

\section{DAFTAR PUSTAKA}

1. IIED. 2002. Breaking new ground: the report of the Mining, Minerals, and Sustainable Development Project, May 2002. International Institute for Environment and Development and World Business Council for Sustainable Development. $410 \mathrm{p}$.

2. ITRC. 2009. Phytotechnology Technical and Regulatory Guidance and Decision Trees, Revised. The Interstate Technology \& Regulatory Council. 125 p + App.

3. Vangronsveld J, R Herzig. N Weyens, $\mathrm{J}$ Boulet, K Adriaensen, A Ruttens, T Thewys, A Vassilev, E Meers, E Nehnevajova, D van der Lelie, M Mench. 2009. Phytoremediation of contaminated soils and groundwater: lessons from the field. Environ Sci Pollut Res. 16:765-794.

4. Jing, W., Z. Zhang, Y. Su, W. He, F. He and $\mathrm{H}$. Song. 2008. Phytoremediation of petroleum polluted soil. Pet. Sci. 5:167-171.

5. Truu, J., L. Kärme, E. Talpsep, E. Heinaru, E. Vedler, A. Heinaru. 2003. Phytoremediation of Solid Oil Shale Waste from the Chemical Industry. Acta Biotechnol. 23:301-307.

6. Wang, J., Z. Zhang, Y. Su, W. He, F. He, and $H$. Song. 2008. Phytoremediation of petroleum polluted soil. Pet. Sci. 5:167-171.
7. Muratova, A., Th. Hübner, S. Tischer, O. Turkovskaya, M. Möder, and P. Kuschk. 2003. Plant —Rhizosphere-Microflora Association During Phytoremediation of PAH-Contaminated Soil. Int. J. Phytorem. 5:137-151.

8. BSN. 2004a. Air dan air limbah - Bagian 11: Cara uji derajat keasaman $(\mathrm{pH})$ dengan menggunakan alat $\mathrm{pH}$ meter. SNI-06-6989.11-2004.

9. BSN. 2004b. Air dan air limbah - Bagian 1: Cara uji daya hantar listrik (DHL). SNI 06-6989.1-2004.

10. EPA. 1996. Method 3540C Soxhlet Extraction. In Test methods for evaluating solid waste. Physical/ chamical methods. Integrated manual (SW-846). Third edition.

11. Steel, R.G.D. dan J.H. Torrie. 1989. Prinsip dan Prosedur Statistika. Suatu Pendekatan Biometrik. Edisi kedua. Alihbahasa: Bambang Sumantri. Penerbit PT Gramedia, Jakarta. 748 hal.

12. Kaimi, E., T. Mukaidani, S. Miyoshi, and M. Tamaki. 2006. Ryegrass enhancement of biodegradation in diesel-contaminated soil. Environmental and Experimental Botany. 55:110-119.

13. Kechavarzi, C., K. Pettersson, P. Leeds-Harrison, L. Ritchie, and S. Ledin. 2007. Root establishment of perennial ryegrass (L. perenne) in diesel contaminated subsurface soil layers. Environmental Pollution. 145:68-74. 